\title{
Memória, mídia e imaginário social: o caso Porongos
}

\section{Cristian Jobi Salaini}

Universidade Federal do Rio Grande do Sul

E-mail: salaini@gmail.com

\section{Ana Paula Comin de Carvalho}

\author{
Universidade Federal do Recôncavo Bahiano \\ E-mail: anapaulacomin@yahoo.com.br
}




\section{Resumo}

O objetivo deste artigo é demonstrar um caso em que elementos midiáticos serviram como ponto de alimentação em uma polêmica que se articula à produção de imaginário social, memória coletiva e identidades étnicas no Rio Grande do Sul: trata-se do "caso Porongos". A evocação desse episódio da história do estado traz, hoje, a possibilidade de evidenciar a participação negra em momentos emblemáticos da história regional, como a Revolução Farroupilha. Pode-se dizer que a mídia atua como elemento indissociável da produção da memória coletiva rearticulada nessa questão. Nosso argumento central aqui gira em torno da possibilidade da apropriação de recursos simbólicos considerados mais ou menos legítimos, no processo social, por diferentes agentes construtores da polêmica, em que alguns elementos midiáticos, em especial, de uma minissérie exibida pela Rede Globo de Televisão em 2003 - A casa das sete mulheres - e de um filme produzido em 2001 - Netto perde sua alma - tiveram papel fundamental no desencadeamento de produção de identidades étnicas e reformulações a respeito de um evento conhecido da história da Revolução Farroupilha: a Batalha de Porongos. O interesse central é evidenciar o papel da mídia como um "potencializador" de evocação identitária de sujeitos e grupos que possuem como projeto fundamental a revisão de elementos da história através da ação da memória e de imaginários sociais.

Palavras-chave: mídia; memória social; identidade étnica; Batalha de Porongos; Rio Grande do Sul.
Abstract

This essay explores a controversy around the social imaginary, collective memory and ethnic identity in Rio Grande do Sul, as played out by media representations of the Battle of Porongos. The evocation of this historical episode of the state brings forth blacks' participation in emblematic events in regional history, such as the Farroupiplha Revolution. The media acts as an inextricable element of the production of social memory of this event. Our main argument here revolves around the issue of symbolic appropriations by different agents in a polemic around this historical event. In particular, we turn to the TV series A Casa das Sete Mulheres (TV Globo 2003) and the film "Netto perde sua alma" (2003), which played a significant part in the formulation of ethnic identity and recasting the historical event. We seek to point to media's potential to catalyze identity for subjects and groups which aim to revise history through the appeal to memory and the social imaginary.

Keywords: media; social memory; ethnic identity; Porongos Battle; Rio Grande do Sul. 
$\mathrm{O}$ objetivo deste texto é demonstrar um caso em que elementos midiáticos serviram como ponto de alimentação em uma polêmica que se articula à produção de imaginário social, memória coletiva e identidades étnicas no Rio Grande do Sul: trata-se do "caso Porongos". A evocação desse episódio da história do Rio Grande do Sul traz, hoje, a possibilidade de evidenciar a participação negra em momentos emblemáticos da história regional, como a Revolução Farroupilha.

A polêmica que conduz o episódio (e que encontra num dos campos argumentativos a possibilidade de os combatentes negros terem sido traídos pelos líderes farroupilhas, no momento final da referida revolução) ${ }^{1}$ é desenvolvida tradicionalmente pelo campo da historiografia. Porém, em especial nos últimos seis anos, ela vem ganhando força pela ação dos movimentos sociais do Rio Grande do Sul, tornando-se alvo, inclusive, de políticas públicas na área do patrimônio cultural dirigidas pelo Instituto do Patrimônio Histórico e Artístico Nacional (IPHAN). Esse fato desembocou na construção de um Inventário Nacional de Referências Culturais (INRC) com o objetivo de levantamento de "bens culturais" sobre a batalha. Isso possibilitou nossa imersão etnográfica em grupos, celebrações e situações diversas que envolvem o tema. ${ }^{2}$

Temos, assim, a construção de um fato social que dialoga com a história regional, mas que encontra, sobretudo, elementos capazes de "transcender" certos limites propostos pela discussão historiográfica. Pode-se dizer que a mídia atua como elemento indissociável da produção da memória coletiva (Halbawchs, 1990) rearticulada nessa questão.

ILHA

volume 10 - número 2 
Nosso argumento central aqui gira em torno da possibilidade da apropriação de recursos simbólicos considerados mais ou menos legítimos, no processo social, por diferentes agentes construtores da polêmica, em que alguns elementos midiáticos, em especial, de uma minissérie exibida pela Rede Globo de Televisão em 2003 - A casa das sete mulheres - e de um filme produzido em 2001 - Netto perde sua alma - tiveram papel fundamental no desencadeamento de produção de identidades étnicas e reformulações a respeito de um evento conhecido da história da Revolução Farroupilha: a Batalha de Porongos.

Não se argumenta aqui, contudo, um protagonismo da mídia sobre outras escalas sociais; o objetivo é, sobretudo, trazer à tona um diagrama social em que a produção identitária de personagens da ficção televisiva e cinematográfica foi amplificada pelos elementos identitários já possíveis em outros níveis sociais, produzindo novos sentidos. O interesse central aqui é, portanto, evidenciar o papel da mídia como um "potencializador" de evocação identitária de sujeitos e grupos que possuem como projeto fundamental a revisão de elementos da história através da ação da memória e do imaginário sociais.

Em 14 de setembro de 2001 foi lançado o filme Netto perde sua alma, dirigido por Beto Souza e Tabajara Ruas, baseado no romance homônimo deste último. Na película o General Antonio de Souza Netto, interpretado pelo ator Werner Schünemann, ferido durante a Guerra do Paraguai (1861-1866), é recolhido ao Hospital Militar de Corrientes, Argentina, onde, sedado pela morfina, trava o acerto de contas com os fantasmas e as culpas que assombram a sua memória. Numa madrugada, ele recebe a visita do Sargento Caldeira, interpretado pelo ator Sirmar Antunes, ${ }^{3}$ que comandou, sob suas ordens, o destacamento dos lanceiros negros durante a Guerra dos Farrapos. Juntos rememoram o passado comum, em especial a revolta dos soldados negros sobreviventes ao fim do conflito. ${ }^{4}$ A produção cinematográfica, exibida nos cinemas durante a semana das comemorações da Revolução Farroupilha no estado, dá maior visibilidade e fomenta a polêmica que cerca o ataque aos lanceiros negros entre círculos mais amplos da sociedade. Outrossim, ela apresenta personagens, o

ILHA

volume 10 - número 2 
Sargento Caldeira e o jovem lanceiro Milonga, com os quais os espectadores negros podem passar a se identificar. ${ }^{5}$

\begin{abstract}
Antes de eu fazer o filme [Netto perde sua alma] eu já tinha conhecimento da história da revolução farroupilha porque tinha um personagem que eu fazia nas minhas performances que é um lanceiro que vem pra contar o que aconteceu na guerra... mas foi pós era escolar que eu fui pesquisar, fui aprender com as pessoas do movimento negro, com os poetas... quando eu comecei dizer poesias sobre os lanceiros negros, fui pesquisar e aprendi. Então quando o filme "Netto perde sua alma" pintou houve um mergulho muito grande... de tudo que fazia parte do universo daquele filme... e obviamente no que me tocava eu fui pesquisar muito mais os lanceiros... conversei muito com o historiador Guarani Santos e o professor Oliveira Silveira. E ai aprendi muito sobre os lanceiros... até dei uns toques para o Tabajara Ruas... toques que não eram do conhecimento total da equipe e isso para mim foi gratificante. E naquele momento que a gente iniciou o filme, em 1999... em 2000 a gente montou eu e Ney Ortiz os lanceiros negros na Revolução Farroupilha, um espetáculo de dança onde eu fazia um próprio lanceiro contando a história... era basicamente o que eu já fazia só que agora com grupo de dança, músicos, etc. e tal. [...] No dia 14 de setembro [ano de 2000] eu fiz uma performance no palácio Piratini e as pessoas não esperavam... não sabiam o que iam ver... mas a forma como eu fiz, a própria roupa do filme, do Netto, roupa cenografada... como se tivesse saído da guerra, foi impactante. E dizendo, no palácio... um texto dizendo assim: "Nós gaúchos nos orgulhamos de nossa história... nós gaúchos enquanto estado... desculpe negrada, nós fal hamos com vocês!". Então foi uma honra para mim dizer isso dentro do Palácio Piratini na presença do Governador Olívio Dutra, ele se emocionou chorando e sorrindo [...] (Sirmar Antunes, em entrevista em 2005).
\end{abstract}

O ator Sirmar Antunes, em função de sua participação em Netto perde sua alma, passa a ser notoriamente reconhecido, publicamente, como o "lanceiro negro contemporâneo". O senador Paulo Paim criou, durante o ano de 2004, o troféu Lanceiros Negros, ${ }^{6}$ evidenci-

ILHA

volume 10 - número 2 
ando como o "lanceiro" passa a ser um signo acionado e atualizado em situações diversas. Durante a ocasião na qual é criado tal troféu, a figura de Sirmar Antunes e, por extensão, sua associação semântica com o filme parecem dirigir o momento, conforme nota exibida no site do Senado Federal, em 17 de abril de 2004, intitulada "Emoção marca o lançamento do troféu Lanceiros Negros":

Uma noite carregada de emoção e homenagens marcou o lançamento do troféu Lanceiros Negros, realizado no último sábado (15) na Sociedade Canoense de Caça e Pesca, em Canoas. Com um público de cerca de 500 pessoas - entre elas a atriz global Sharon Menezes e os pais da ginasta olímpica Daiane dos Santos - a solenidade teve início com a exibição de cenas do filme "Netto perde sua alma", de Tabajara Ruas e com a apresentação teatral do ator gaúcho Sirmar Antunes, que interpretou um lanceiro negro. Na ocasião, o senador Paulo Paim destacou que a história dos lanceiros negros deve ficar registrada como a luta de um povo que ofereceu sua vida pela liberdade e pela igualdade dos homens. "Criamos este troféu para lembrar que todos nós, brancos e negros, também somos lanceiros, pois devemos lutar como eles lutaram em defesa da liberdade, da igualdade e da justiça", afirmou. O parlamentar disse ainda que a intenção do troféu é premiar personalidades, entidades públicas e privadas, bem como associações e sindicatos que estejam contribuindo para a cidadania de afro descendentes, idosos, portadores de deficiência, crianças e diversos outros setores que estejam às margens da sociedade. A entrega do troféu deverá ser realizada em 14 de novembro do corrente ano (Portal Senadores, 2008).

Desde então, Sirmar Antunes é chamado a participar - na condição de especialista no assunto - em eventos diversos que discutem a "controvérsia de Porongos", sendo frequentemente chamado a proferir palestras sobre o tema. Suas perfomances artísticas (declamações, monólogos, atuações teatrais) passam a ser conhecidas do público e, ao serem conectadas a situações promovidas por outros grupos do Rio Grande do Sul e do Brasil, conferem notoriedade e reconhecimento sociais aos grupos e às situações promovidas. Em nosso contato etnográfico com os diferentes grupos que evocam a

ILHA

volume 10 - número 2 
temática, na atualidade, o ator foi frequentemente referenciado como um "professor" do tema, uma "matriz" a ser utilizada. Durante as comemorações da Semana Farroupilha de 2005, em Porto Alegre, o ator desenvolveu uma palestra sobre o tema no "Piquete dos Inapiários". Nas instalações do piquete era exibida uma representação de um lanceiro negro baseada na participação de Sirmar em Netto perde sua alma.

Nos dias 13 e 14 de novembro de 2004 houve uma série de atividades, na cidade de Pinheiro Machado, Rio Grande do Sul, ${ }^{7} \mathrm{em}$ homenagem aos lanceiros negros. O ponto alto de tal encontro seria a inauguração, no dia 14, de uma pedra fundamental que serviria de ponto de partida à construção do Memorial aos Lanceiros Negros ${ }^{8}$ no Cerro de Porongos, reconhecido como local da batalha e localizado nessa cidade. ${ }^{9}$

Durante as atividades que envolveram essa celebração em Pinheiro Machado, Sirmar Antunes ocupou lugar de destaque. Na noite do dia 13 o ator fez papel de narrador durante a exibição da peça teatral Lanceiros Negros, dirigida por Ney Ortiz, diretor do Centro Cultural Raízes d'África. O ator, que na ocasião vestia roupas vermelhas e rasgadas, aponta que é o momento de o Rio Grande do Sul presenciar um "batuque com churrasco", um "Ogum comendo churrasco" e um "batuque de bombacha", realizando conexão entre elementos tidos como representativos de um imaginário afro-brasileiro e de um imaginário gaúcho, respectivamente. Faz-se necessário, segundo ele, ativar a consciência dos "lanceiros negros de hoje", sendo esse não mais o momento do "uso de lanças, e sim de políticas afirmativas". Cabe notar que essa ocasião contou com a presença de representantes dos governos Federal, Estadual e Municipal, além de movimentos sociais de forma ampla.

O objetivo aqui foi demonstrar, de forma breve (poderíamos buscar uma série de outros exemplos), como uma produção fílmica pode articular-se com elementos da memória coletiva regional, apresentando uma "efervescência" de práticas identitárias promovidas por grupos preocupados em revisar a participação negra na construção representacional regional. Essa produção, ao projetar Sirmar

ILHA

volume 10 - número 2 
Antunes em outros planos de interpretação do social, promoveu um processo de retroalimentação entre a história e a performance, consolidando um elemento de apoio às demandas de grupos sociais. Em 2008 será lançando Netto e o domador, também dirigido por Tabajara Ruas. O filme aprofunda o processo de recrutamento dos lanceiros negros pelo General Netto, trata-se de uma continuação de Netto perde sua alma, e Sirmar Antunes ocupa um dos papéis principais.

Seguindo o mesmo eixo argumentativo, veremos a seguir aspectos da relação desempenhada pela exibição da minissérie $A$ casa das sete mulheres em nosso universo de pesquisa.

Entre 07 de janeiro e 08 de abril de 2003 a rede de televisão Globo exibiu a minissérie $A$ casa das sete mulheres, livre adaptação do romance homônimo da escritora Letícia Wierzchowski, dirigida por Jayme Monjardim e Marcos Schechtmann. Ela aborda a Guerra dos Farrapos a partir das experiências de mulheres que pertenceriam à família de Bento Gonçalves e que, em função do conflito, passaram a viver isoladas em uma estância, sendo visitadas volta e meia pelos homens - seus parentes, conhecidos e pretendentes -, que foram para a batalha. Em um dos episódios o General David Canabarro envia um emissário para sondar o imperial Francisco Pedro de Abreu, o "Moringue", sobre suas intenções naquele período de tratativas de paz. Ao ser informado que este último desejava evitar derramamento de sangue, Canabarro se despreocupa e vai ficar com sua amante "Papagaia". Durante a noite o acampamento é atacado pelas tropas imperiais. O general farrapo, surpreendido, ordena ao Coronel Teixeira Nunes que os lanceiros negros façam a retaguarda do exército farrapo para facilitar a fuga e permitir que ele se organizasse para enfrentar o inimigo em melhores condições. Os soldados escravos não fugiram como os demais e guerrearam com um destemor considerado sobrenatural e a influência sagrada de alguma divindade africana. O massacre dos lanceiros naquela noite suscita a suspeita de uma traição, já que o império brasileiro era contrário à ideia de concederlhes a liberdade.

ILHA

volume 10 - número 2 
O Governo Estadual da época, administrado por Germano Rigotto, do Partido do Movimento Democrático Brasileiro (PMDB), buscava, principalmente através da Secretaria de Esporte, Lazer e Turismo, sob a responsabilidade de Luiz Augusto Lara, do Partido Trabalhista Brasileiro (PTB), divulgar as belas paisagens do Rio Grande do Sul a partir de produções audiovisuais de ampla divulgação. Nesse sentido, desenvolvia um trabalho de atração dessas atividades para a região com a expectativa de despertar o interesse de turistas de outros lugares do Brasil. ${ }^{10}$ Com a exibição da minissérie, a potencialidade do turismo histórico, ligado a fatos da Revolução Farroupilha, ficou ainda mais evidente para os políticos locais. Todavia, a difusão proporcionada pela minissérie teve outras consequências, como veremos a seguir.

Em 2003 configurou-se uma Comissão ao Memorial aos Lanceiros Negros encarregada de dirigir atividades relacionadas ao Projeto Porongos. Essa comissão tinha como objetivo fundamental a discussão em torno da formatação das atividades de construção do Memorial aos Lanceiros Negros, assim como a organização de atividades relacionadas com as celebrações que ocorrem anualmente em Pinheiro Machado. Essa comissão encontrava, em seu corpo, integrantes do Movimento Tradicionalista Gaúcho (MTG) e do Instituto Gaúcho de Tradição e Folclore (IGTF) e integrantes do Movimento Negro de várias localidades do Rio Grande do Sul, além do grupo artístico Raízes d'África e de representantes da Secretaria de Cultura e da Secretaria da Educação do estado.

A administração pública da cidade de Pinheiro Machado é procurada, ainda em 2002, por agentes do Movimento Negro ${ }^{11}$ - o Centro Cultural Cândido Velho, de Guaíba, protagonizou essas primeiras tratativas - com o objetivo de realizar as "movimentações" relacionadas à construção do Memorial em homenagem aos combatentes negros naquela cidade. Edison Manoel Molina de Oliveira, secretário de Cultura e Turismo da cidade naquele momento, nos narrou em $2004^{12}$ que ele se interessou pelo assunto em função da inexistência de pontos turísticos em Pinheiro Machado. Naquele momento, o prefeito não teria dado a devida importância a esse pro-

ILHA

volume 10 - número 2 
jeto e somente após a exibição da minissérie $A$ casa das sete mulheres é que a prefeitura e o governo do estado abraçaram esse empreendimento, segundo o ex-secretário. ${ }^{13}$

As discussões fomentadas pela exibição da minissérie não apenas motivaram quem dela participou a aprofundar seus conhecimentos sobre o assunto, mas também tiveram impactos na atuação da administração estadual, que vinha sendo pressionada há algum tempo por militantes dos movimentos sociais negros a promover políticas públicas de reconhecimento e valorização da história dos afrodescendentes na região. Dessa forma, o Governo do Rio Grande do Sul contatou a Fundação Cultural Palmares, ligada ao Ministério da Cultura (MinC), para ajudá-lo a viabilizar a construção do Memorial aos Lanceiros Negros.

Parte dos figurantes que interpretaram o batalhão de lanceiros negros $\mathrm{n} A$ casa das sete mulheres era integrante do Centro de Tradições Gaúchas Clareira da Mata, de Caçapava do Sul, fundado por negros que não podiam frequentar agremiações do mesmo tipo na cidade por causa de sua raça/cor. Após a experiência de representar os escravos que lutavam no exército farrapo sob a promessa de liberdade, eles continuaram participando de atividades culturais como lanceiros negros. Em entrevista com o grupo, José Almiro Pereira Alves nos narrou como o tema "Lanceiros Negros" tornou-se central após a participação do grupo na minissérie:

Não, na verdade foi depois. Porque o patrão do CTG na época era outro que antecedeu essa patronagem que está agora, e ele também participou nas gravações. E depois nós voltamos de lá e a gente ficou meio... foi comentado a participação do pessoal de Caçapava na minissérie e aí o patrão fez uma janta e tal, envolveu os lanceiros, mas com a finalidade de angariar dinheiro. Ele não teve a preocupação com história, com absolutamente nada a esse respeito. A finalidade dele, a intenção dele, foi na verdade usar os lanceiros para fazer dinheiro para o CTG. Aí no momento que trocou a patronagem nós assumimos. Eu sou da patronagem, o Tita que é o patrão do CTG também é. Aí eu mesmo falei para ele: - Olha, no momento que nós estamos assumindo o CTG porque o patrão anterior fez jantas e promoções usando o

ILHA

volume 10 - número 2 
nome dos lanceiros, nós temos a obrigação de fazer uma reunião e ver se nós vamos continuar o grupo ou se nós terminamos com ele. Porque, na verdade, Caçapava, toda a comunidade, de uma certa forma, naquelas promoções que ele fez o pessoal se envolveu, o comércio de Caçapava doou. Então a gente tinha um compromisso moral com a comunidade de dar uma satisfação. Ou nós continuamos com o grupo, mas continuamos com o grupo organizado, com a finalidade que deveria ter que é a pesquisa, que é a história, ou então terminamos o grupo. Então no dia onze de julho de 2004 nós nos reunimos aqui nesse galpão e por unanimidade o pessoal concordou em fundar o grupo. A partir dai nós continuamos organizando, trabalhando na organização, na aquisição de indumentárias. Coisa bastante difícil. A gente, questão de dinheiro não é fácil. Então, graças a Deus, hoje nós estamos com o grupo já (José Almiro Pereira Alves, em entrevista em 2005).

O grupo, hoje, procura outras referências que lhe deem continuidade. Exemplo disso é a existência, na formação do grupo, de uma figurinista que apoia a caracterização dos "Lanceiros Negros" nas atividades protagonizados por ele.

Os "Lanceiros Negros" passam a existir após a participação $\mathrm{n} A$ casa das sete mulheres. Esse fato presume uma apropriação simbólica efetuada pelo grupo no sentido de dar continuidade a um tipo de solidariedade étnica que já existia antes na forma do CTG Negro. Todavia, ao realocar um espaço específico aos lanceiros negros dentro desse CTG, o grupo elabora uma memória específica em relação a tal evento. Essa memória não encontra referência direta em seus passados familiares. Ela é elaborada no curso dos eventos de que o grupo participa e na "busca" de referência e "pesquisas" que deem fundamento ao objetivo desse grupo. Esse fato coloca-o na posição de diálogo com o imaginário existente sobre tal evento, assim como o papel do negro nesse mesmo evento.

Por fim, cabe notar o "reconhecimento" por parte dos produtores da RBS $\mathrm{TV}^{14}$ do grupo como representante "legítimo" dos lanceiros negros. Durante a Semana Farroupilha em 2005, a RBS TV exibiu o programa intitulado "Rio Grande sem fronteiras". Nesse

ILHA

volume 10 - número 2 
programa, vários especialistas teceram comentários sobre a Revolução Farroupilha de forma geral e, pontualmente, sobre a Batalha de Porongos. No final desse programa, os "Lanceiros Negros" foram exibidos e, já nos "letreiros finais", foi exibida a música "Conquistando a liberdade", de autoria de Daltro, integrante do grupo.

Durante a produção do Inventário Nacional de Referências Culturais (INRC) sobre o "Massacre de Porongos", tivemos contato com Santa Eulália Souza Dutra, conhecida localmente como "Dona Santinha" e uma das fundadoras do movimento negro local Zumbi dos Palmares. Durante o processo de pesquisa, realizamos entrevistas com ela em diferentes momentos, e as narrativas produzidas geraram, no grupo de pesquisa, uma série de conjecturas sobre a possibilidade de se "mesclarem" elementos familiares - e portanto locais - com elementos ficcionais da minissérie. A questão é que, normalmente, ao contar as histórias sobre Porongos, Dona Santinha sempre apresentou a memória de seu Tio Quinca como elemento fundamental a ser apresentado sobre os fatos que teriam ocorrido no Cerro de Porongos. Porém, em outras situações das entrevistas, Dona Santinha pareceu ter trazido alguns elementos, em sua narrativa, que nos desenharam a possibilidade de se "mesclarem" elementos com a minissérie em questão.

Quem tinha falado dos lanceiros tinha sido o seu Quinca, um senhor que hoje estaria com cento e poucos anos. A gente foi numa festa, ai ele me mostrou que ali naquele local tin ha havido o massacre dos negros. Eles se esconderam ali naquele cerro, na luta, para brigar e ai vieram e atacaram. E eles iludiram os negros, eles mentiram para os negros que estava tudo bem e desarmaram os negros, mandaram que se desarmassem, que entregasse as armas. Claro, foi por causa da assinatura, que eles iam assinar a libertação deles. E eles largaram as armas. Ele contou que ali tinham feito um buraco - como é o nome daquela erva? De chirca; ela estava altae os negros deitaram. Mandaram os negros largarem as armase deitarem ali, na paz, e ali mataram os negros tudo (Dona Santinha, em entrevista em 2005).

Outra fala:

Os coronéis disseram pra eles... e tavam tudo armados os negros né... esperando parar a guerra e eles aí eles começaram... chegaram

ILHA

volume 10 - número 2 
com aquela bandeira de paz e disseram pros negros que eles queriam paz e que os negros estavam ali pra se render e que eles largassem as armas. Então fizeram um círculo redondo e mandaram que os negros largassem as armas ali. Quando os negros ficaram desarmados eles mandaram os negros tudo se deitá e ali mataram. Então foi uma traição pros negros né (Dona Santinha, em entrevista em 2005, grifo nosso).

Foi inevitável o levantamento de hipótese, por parte do grupo de pesquisa, da estruturação de uma narrativa, por Dona Santinha, que revelava alguns elementos muito semelhantes àqueles mostrados em momentos finais da minissérie $A$ casa das sete mulheres. Nesse sentido, ocorreria aqui um "amalgamento" entre memórias de sua trajetória pessoal - as memórias do Tio Quinca - e o "script" fornecido pelo elemento midiático. Ao realizar essa operação, a narrativa local, contida nos limites da transmissão familiar, ganharia um outro corpo mais legítimo por "tomar de empréstimo" a estrutura televisiva, dela apropriando-se e ampliando-a.

Nosso objetivo aqui foi trazer um caso de produção de identidades sociais que contou, em seu movimento de construção, com uma intersecção entre os campos da mídia, da memória e do imaginário social. Como firmamos em nosso argumento central, não se trata de demonstrar um protagonismo da mídia na consecução dos processos sociais que envolvem a polêmica em torno de Porongos. A ideia foi dirigir o olhar a um processo em que elementos oriundos de quadros midiáticos "efervesceram" a produção de memórias e identidades. Sem dúvida, nenhum dos roteiros das duas produções citadas aqui tinha como eixo central de suas narrativas o caso Porongos e/ ou lanceiros negros, mesmo que o tema tenha sido abordado nos dois casos. Porém, acabaram por se revelar constituintes dessa circularidade da cultura que provocou apropriações em diferentes sentidos. O que nos interessou aqui foi evidenciar esse movimento de diálogo de campos que privilegiou a legitimação de uma identidade étnica no Rio Grande do Sul através da releitura desse evento do passado.

ILHA

volume 10 - número 2 
O ator gaúcho Sirmar Antunes, ao participar do longa-metragem Netto perde sua alma, se constitui como sujeito legítimo a falar do assunto. Isso fica evidente nos diferentes momentos em que foi e é chamado por diferentes grupos na busca de construção de espaços de legitimidade, tornando-se uma metáfora da figura do lanceiro negro. Como vimos, a exibição da minissérie $A$ casa das sete mulheres extrapolou seu espaço de atuação, transformando-se num elemento desencadeador de questionamentos sobre a "real" história da participação negra na Revolução Farroupilha. Além disso, tornou-se elemento legitimador de práticas no campo das políticas públicas, imiscuindo-se em narrativas de atores sociais orientadas ao tema, como o caso de Dona Santinha, por exemplo.

Temos, assim, um caso particular de memória coletiva acionada com a finalidade de criação de um espaço étnico, um espaço de reconhecimento da presença negra no Rio Grande do Sul em momentos fundamentais de sua história. Estabelece-se uma relação dinâmica entre história e memória, já que determinados elementos e cenários políticos atuais revisam o local do negro na história regional: é a própria ação social desses grupos que promove essa releitura retrospectiva do passado. Os grupos são conformados porque há uma memória coletiva, e não o contrário (Halbwachs, 1990).

Estamos aqui tentando demonstrar essa relação dinâmica entre o "real" e a "ficção" como conformadores do mesmo circuito simbólico. De fato, elementos do universo midiático se misturaram a outros (experiências e narrativas pessoais, possibilidades políticas, por exemplo), gerando consequências nos espaços sociais. Assim entramos no campo do imaginário social, que, segundo a tendência das ciências humanas, cada vez menos é entendido como "ilusão" ou como algo pertencente ao domínio do "fantástico". Pelo contrário, é através do imaginário e do conjunto simbólico proposto por ele que é possível aos grupos e aos indivíduos a aquisição de posições no mundo. É preciso estar atento para as técnicas de difusão do imaginário que são enfatizadas dependendo da conjuntura histórica específica, e, portanto, “a elaboração e aprendizagem das práticas e técnicas de manejamento dos imaginários sociais, têm prioridade sobre

ILHA

volume 10 - número 2 
qualquer reflexão teórica" (Baczko, 1985, p. 299). Segundo o autor, portanto, não há como opor ou dissociar "ilusão" e "real", como fazia Marx:

Recordamos já as páginas em que Marx opõe a Revolução Francesa, que disfarçava os seus atores com trajos antigos, à sua visão da revolução proletária, cujos actores dispensariam qualquer máscara. Porém, em nenhum caminho da sua história, nem mesmo caminhos da revolução, seja ela "burguesa" ou outra, os homens passeiam nus. Precisam de "fatos", de signos e imagens, de gestos e figuras, a fim de comunicarem entre si e se reconhecerem ao longo do caminho. Os sonhos e as esperanças sociais, freqüentemente vagos e contraditórios, procuram cristalizar-se e andam em busca de uma linguagem e de modos de expressão que os tornem comunicáveis (Baczko, 1985, p. 321).

Evidencia-se uma apropriação por parte dos atores sociais envolvidos que revela a circularidade da cultura e a agência dos grupos envolvidos no sentido da evocação de uma memória coletiva através da utilização de técnicas de difusão do imaginário social. Nesse processo de construção de memória e imaginário sociais a respeito desse evento emblemático da história do Rio Grande do Sul, a mídia foi usada no sentido de ampliar, divulgar e angariar legitimidade à construção desse processo identitário, na mesma direção apontada por outros pesquisadores:

Se trabalhássemos procurando na construção da mensagem não aquilo que o seu produtor planejou, mas o que as pessoas que não são profissionais da comunicação estão fazendo dentro dessas mensagens, poderíamos talvez ver riquezas de estratégias construídas para aparecer na televisão, para se comunicar com parentes, amigos, namorados, através da televisão, enfim para se relacionar socialmente. Aproveitando pequenas enquetes, entrevistas, jogos de futebol, programas de auditório [...] e outros, as pessoas se apropriam da linguagem televisiva, transformamse também em imagem, que serão reinterpretadas de vários modos, e transformam o modo de se comunicar. Creio que este enfoque já está de certo modo contemplado na análise proposta por Martín-Barbero: para entender o processo de

ILHA

volume 10 - número 2 
comunicação, ele propõe analisar não só a recepção, mas a produção, a emissão e as mediações que estão presentes tanto em um pólo como no outro. Mas creio que a agência das pessoas para que a construção de imagens e textos televisivos se dê numa direção diferente da planejada pelos produtores, não tem sido suficientemente destacada. Com a crítica ao centramento feito no emissor por anos e (décadas) de pesquisa, parece que as iniciativas neste campo ainda são tímidas (Magalhães, 2004, p. 284).

Obviamente, o "caso Porongos" não foi criado pela mídia. A narrativa historiográfica local apresenta um quadro de historiadores preocupados com a polêmica já desde o final do século XIX. ${ }^{15} \mathrm{Na}$ atualidade, os movimentos sociais procuram revisar o peso dado à participação negra na Revolução Farroupilha e, por extensão, na história do Rio Grande do Sul de forma mais ampla. Os sujeitos evocam essa "memória de Porongos" utilizando como quadros possíveis de evocação suas vivências nos movimentos sociais e suas vivências familiares. Essa representação mais geral sobre o evento do passado acaba funcionando como um quadro mais geral no qual os grupos e os sujeitos apoiam-se ao legitimar suas práticas e memórias (Salaini, 2006).

Nesse contexto, os elementos apresentados pelos produtores midiáticos "alimentaram" esse quadro geral de evocação da memória, ora, não é acaso que as movimentações em torno da construção do Memorial aos Lanceiros Negros na cidade de Pinheiro Machado tenha ocorrido de forma ligeiramente posterior à exibição das duas produções acima citadas. Isso sem contar as inúmeras celebrações, festividades e grupos que memorizam o caso nos últimos anos. O que se firma aqui, no enfoque que conduz o nosso texto, é a agência dos sujeitos nesse empreendimento de leitura e releitura dos produtos midiáticos, que, por sua vez, também são entendidos aqui como elementos da cultura.

\section{Referências}

A CASA das sete mulheres. Direção de Jayme Monjardim e Marcos Schechtmann. Rede Globo, 2003.

ILHA

volume 10 - número 2 
ALVES, Caleb Faria. Benedito Calixto e a construção do imaginário republicano. Bauru: EDUSC, 2003.

BACZKO, Bronislaw. Imaginação social. In: ENCICLOPÉDIA Einaudi. Lisboa: Imprensa Nacional/Casa da Moeda, 1985. v. 5.

BAKOS, Margaret Marchiori. A escravidão negra e os farrapos. In: DACANAL, José Hildebrando et al. (Org.). A Revolução Farroupilha: história e interpretação. Porto Alegre: Mercado Aberto, 1985. p. 124-138.

BANTON, Michael. Etnogênese. In: . A idéia de raça. São Paulo: Edições 70/Martins Fontes, 1977. cap. VIII.

BARCELLOS, Daisy M. 1996. Família e ascensão social de negros em Porto Alegre. Tese (Doutorado) - Programa de Pós-Graduação em Antropologia Social, Museu Nacional, UFRJ, Rio de Janeiro, 1996.

BARTH, Frederik. Grupos étnicos e suas fronteiras. In: POUTIGNAT, Philippe; STREIFF-FENART, Jocelyne. Teorias de etnicidade. São Paulo: UNESP, 1997.

. Temáticas permanentes e emergentes na análise da etnicidade. In: VERMEULEN, Hans; GOVERS, Cora (Org). Antropologia da etnicidade para além de "Ethnic Groups and Boundaries". Lisboa: Fim de Século, 2003. p. 19-44.

BOURDIEU, Pierre. Economia das trocas simbólicas. São Paulo: Perspectiva, 1982. 1989. . O poder simbólico. Lisboa: DIFEL; Rio de Janeiro: Bertrand Brasil,

BRUM, Ceres Karam. Esta terra tem dono. Disputas e representações sobre passado missioneiro no Rio Grande do Sul: a figura de Sepé Tiarajú. Porto Alegre: Manuscrito, 2004.

CARVALHO, José Murilo de. A formação das almas: o imaginário da República no Brasil. São Paulo: Companhia das Letras, 1990.

D’ADESKY, Jacques. Acesso diferenciado dos modos de representação afrobrasileira no espaço público. Revista do Patrimônio Histórico e Artístico Nacional, n. 25, 1997. p. 306-315.

FONSECA, Cecília. Referências culturais: bases para novas políticas de patrimônio. In: CORSINO, Célia Maria et al. Inventário Nacional de Referências Culturais: manual de aplicação. Brasília: IPHAN, 2000. p. 119-133.

FLORES, Moacyr. Modelo político dos farrapos. 3. ed. Porto Alegre: Mercado Aberto, 2001.

GEERTZ, Clifford. A interpretação das culturas. Rio de Janeiro: Zahar, 1978.

HALBWACHS, Maurice. A memória coletiva. São Paulo: Vértice, 1990.

HOBSBAWN, Eric. A invenção das tradições. Rio de Janeiro: Paz e Terra, 1997.

ILHA

volume 10 - número 2 
LEITMAN, Spencer. Negros farrapos: hipocrisia racial no Sul do Brasil no século XIX. In: DACANAL, José Hildebrando (Org). A Revolução Farroupilha: história e interpretação. Porto Alegre: Mercado Aberto, 1997.

MACIEL, Maria Eunice. 1994. Le Gaúcho Bresilien Identite Culturelle Dans lê Sud Du Bresil. Tese (Doutorado), Paris V - René Decartes, Sorbonne, France, 1994.

MAGALHÃES, Nara. 2004. Televisão, uma vilã na sociedade contemporânea: um estudo sobre os modos de ver (a) TV de pessoas pertencentes a grupos de camadas médias. Tese (Doutorado em Antropologia Social) - Programa de Pós-Graduação em Antropologia Social, Universidade Federal de Santa Catarina, Florianópolis, 2004.

NETTO perde sua alma. Direção de Beto Souza e Tabajara Ruas. Brasil. 2001.

OLIVEIRA, Vinicius Pereira de; CARVALHO, Daniela Vallandro de. INRC Massacre de Porongos: etapa de registro. Relatório final das atividades da Equipe de Pesquisa Histórica. 2005.

OLIVEN, Ruben George. A parte e o todo. Rio de Janeiro: Vozes, 1992.

PESAVENTO, Sandra J. Os farrapos... Nossa História, Rio de Janeiro, v. 2, n. 15 , p. 54-58, 2005.

PORTAL SENADORES. Disponível em: < http://www.senado.gov.br/

PAULOPAIM/pages/imprensa/releases/2004/Releases2004/

17052004III.htm>. Acesso em: 29 maio 2008.

SALAINI, Cristian Jobi. "Nossos heróis não morreram": um estudo antropológico sobre formas de "ser negro" e de "ser gaúcho" no estado do Rio Grande do Sul. Dissertação (Mestrado em Antropologia Social) - Programa de Pós-Graduação em Antropologia Social, Universidade Federal do Rio Grande do Sul, Porto Alegre, 2006.

SHOHAT, Ella; STAN, Robert. From the Imperial Family to the Transnational Imaginary: Media Spectatorship in the Age of Globalization. In: WILSON, Rob; DISSANAYAKE, Wilmal (Ed.). Global/Local: Cultural Production and the Transnational Imaginary. Durham and London: Duke University Press, 1996.

\section{Notas:}

1 Fundamentalmente, a polêmica que paira sobre este evento gira em torno da seguinte pergunta: David Canabarro - personagem da história do Rio Grande do Sul e comandante do destacamento de negros em questão - teria agido em atitude de traição com relação aos seus lanceiros negros? A historiografia não apresenta um consenso sobre o fato. Alguns trazem David Canabarro como traidor, já que teria recebido, momentos antes da contenda, uma carta endereçada pelo líder imperial Duque de Caxias ao Coronel Francisco Pedro Moringue - comandante da força imperial que atacou os lanceiros negros no Cerro de Porongos - que continha instru-

ILHA

volume 10 - número 2 
ções referentes ao desarmamento da tropa de lanceiros negros. Outros historiadores defendem o argumento de que essa carta teria sido forjada pelos imperiais com a finalidade de desmoralizar o general David Canabarro (Bakos, 1985; Flores, 2001; Leitman, 1997; Oliveira; Carvalho, 2005; Pesavento, 1985).

2 Ver detalhes em: Salaini, Cristian Jobi. 2004. "Nossos heróis não morreram": um estudo antropológico sobre formas de "ser negro" e de "ser gaúcho" no estado do Rio Grande do Sul. Dissertação (Mestrado em Antropologia Social) - Programa de PósGraduação em Antropologia Social, Universidade Federal do Rio Grande do Sul, Porto Alegre, 2004.

3 Integrante dos movimentos sociais negros da Região Metropolitana da capital do estado. Participou ativamente de diferentes eventos relacionados aos lanceiros negros desde a sua participação nesse filme, declamando poesias sobre o tema do militante negro Oliveira Silveira atuante na capital.

4 A produção recebeu quatro Kikitos (troféus) no Festival de Cinema de Gramado, realizado de 6 a 11 de agosto de 2001, na serra gaúcha, nas categorias de montagem, música, prêmio especial do júri e júri popular.

5 A mídia pode contribuir para a formação de comunidades imaginadas e filiações alternativas. O cinema, nesse sentido, pode atuar na conformação de sentimentos identitários. Sobre o assunto, ver Shohat e Stan (1996).

6 O senador indicou a "Família Silva", comunidade que atualmente passa por reconhecimento como "remanescente de quilombo", na cidade de Porto Alegre, para o recebimento de tal troféu.

7 Localiza-se nesta cidade o Cerro de Porongos, local da referida batalha.

8 Houve, em 2005, o lançamento de um edital pelo Instituto de Arquitetos do Brasil (IAB) com a finalidade de construção do Memorial aos Lanceitos Negros em Pinheiro Machado, Rio Grande do Sul.

9 Esta construção é resultado de uma articulação realizada entre a Fundação Cultural Palmares (Ministério da Cultura), a Secretaria de Estado da Cultura do Rio Grande do Sul e a Prefeitura Municipal de Pinheiro Machado. O Centro Cultural Cândido Velho, da cidade de Guaíba, Rio Grande do Sul, ocupou papel fundamental nas iniciativas em torno do Memorial aos Lanceiros Negros.

${ }_{10}$ As cidades que foram os locais cenográficos da minissérie $A$ casa das sete mulheres bem como da novela Chocolate com pimenta, da Rede Globo de Televisão, pagaram a essa emissora para que tais atividades ocorressem nesses municípios.

${ }^{11}$ Com recursos da Câmara Municipal de Guaíba, Luis Mendes, Luis Francisco Barbosa (o Barbosinha) e Waldemar Moura Lima (conhecido como Pernambuco), militantes dos movimentos sociais negros da Região Metropolitana, foram, nessa época, à cidade de Pinheiro Machado conhecer o Cerro de Porongos e contatar a administração municipal para obter apoio para o plano de construção do Memorial.

12 Em conversa realizada como o grupo de pesquisa durante o processo de levantamento preliminar do Inventário Nacional de Referências Culturais “Massacre de Porongos".

13 Ele criou um grupo mirim de danças gaúchas denominado Lanceiros de Porongos em 2002, o qual existe até hoje.

${ }^{14}$ A RBS TV (Rede Brasil Sul de Comunicações) é filiada à Rede Globo de Televisão, sendo a maior emissora do Rio Grande do Sul.

15 Ver detalhes em Oliveira e Carvalho (2005).

Recebido em: 20/06/2008

Aceite em: 09/08/2008

ILHA

volume 10 - número 2 